\title{
FAS 123R: Time to get to work
}

Received (in revised form): 20th July, 2006

\section{Joseph Rosalie}

is National Leader of Global Employer Rewards Practice at Deloitte and has over 25 years of diversified experience. His areas of expertise include retirement plan design, implementation, valuation and termination, long-term deferred compensation plans, post-retirement medical plan valuation, design and funding, merger and acquisition consulting, executive retirement and other deferred compensation arrangements.

\section{Blaise Kah}

leads the Global Employer Rewards service offering for the North Central Region for Deloitte Tax. He and his team focus on the efficient design and delivery of employee benefit and compensation programmes customised to the human resource, tax, cash flow and financial needs of the employer. His nearly 20 years of experience includes consultation in the design and operation of executive compensation arrangements, stock option and equity-based compensation programmes, qualified retirement plans, welfare and fringe benefit plans.

\section{Sean Dineen}

is a principal in the Valuation Services practice of Deloitte Financial Advisory Services LLP ('Deloitte FAS') and leads the Deloitte FAS National Valuation Group's SFAS 123 option valuation practice. He is also the Deloitte FAS representative for the Global Employer Rewards Integrated Service Offering ('GER ISO'). In this role, he serves as the national Deloitte FAS leader for projects related to the GER ISO, primarily focusing on SFAS 123R activities.

Abstract This paper provides a comprehensive perspective of the overlapping requirements of FAS 123R, the American Jobs Creation Act (AJCA) and Sarbanes-Oxley. It details the Deloitte approach to compliance and how this process can generate programme and process improvements that can lead to a competitive advantage.

Pensions (2006) 12, 18-23. doi:10.1057/palgrave.pm.5950034

Keywords: FAS 123R, stock options, options expensing, APIC pool, net excess tax benefits, valuation model

\section{Introduction}

The US corporate landscape shuddered late in 2004 when the Financial Accounting Standards Board (FASB) issued its final standard (FAS 123R) on share-based payments, and the American Jobs Creation Act (AJCA) dramatically changed the tax rules applicable to nonqualified deferred compensation. Until recently, companies were not required to expense the cost of stock options, giving them the ability to provide employee compensation without recording it on the face of the financial statements. New FAS 123R now requires all companies to account for share-based payment awards at fair value and for public companies to record compensation costs for the unvested portion of previously issued awards.

Correspondence: Joseph Rosalie, Deloitte Consulting LLP,

New York, NY, USA

Tel: +12126184734

Email: jrosalie@deloitte.com
As companies come to terms with the requirements of the new standard, they must also consider the regulatory environment and the compliance implications of the rule changes. Consequently, companies across America now find themselves facing the challenge of implementing FAS $123 \mathrm{R}$ and also working to avoid negative earnings repercussions.

Now that companies have had a chance to digest the requirements of the new standard, they need to get down to the business of establishing an implementation approach that addresses all related compliance issues and facilitates the design of incentive plans that actually drive strategic and financial success by creating sustainable long-term shareholder value.

\section{New rules, new implications}

The revised FASB standard and the AJCA rules introduce unprecedented changes in the way 
companies must plan for, issue, disclose and account for equity-based deferred compensation. These changes affect multiple groups across the organisation, including finance and accounting, tax, treasury, human resources, legal, payroll and stock plan administration.

\section{FAS 123R's key provisions}

FAS $123 \mathrm{R}$ requires all US companies, public and non-public, to account for share-based payment awards using a fair-value-based methodology. This is a fundamental change from the requirement of the original standard, Accounting Principles Board Opinion 25, which for more than 30 years allowed companies to employ an intrinsic value method in accounting for share-based payment awards. It also makes mandatory what was only posited as a preference in the original FAS 123, first issued by the FASB in 1995.

As a result, many companies will have to revisit their valuation methodologies, determine and separately track their FAS 123 Additional Paid-in Capital pool of net excess tax benefits (APIC Pool), and re-evaluate their ongoing rewards programmes' design and compliance. The impact of these actions on earnings may be significant for many companies. According to published company financial statements, the impact on prior-year earnings if FAS 123R had been in effect runs the gamut from having little material impact with earnings decreases of 3-4 per cent, to extreme cases in which earnings could be completely wiped out.

At the end of March 2005, the Securities and Exchange Commission (SEC) weighed in on FAS 123R by issuing Staff Accounting Bulletin No. 107 (SAB 107). In SAB 107, the SEC staff provides guidance related to key provisions of FAS $123 \mathrm{R}$, including how it will likely view company decisions relating to valuation methods. Specifically, the staff agreed that companies can choose one of the several valuation methods as long as that method meets all three requirements of the standard. It must be a model that (a) is applied in a manner consistent with the fair value measurement objective and other requirements of FAS 123R; (b) is based on established principles of financial economic theory and generally applied in that field and (c) reflects all substantive characteristics of the instruments.

While the SEC acknowledged the controversial nature of FAS 123R, it implicitly agreed with its provisions, thereby serving notice to US companies that it will uphold the requirements of the standard. In the month following its issuances of SAB 107, however, the SEC extended the deadline for most public companies to comply with FAS 123R. The standard will now be effective for fiscal years beginning after 15th June, 2005. Therefore, companies with a fiscal year of 1st July or after will still have to comply immediately, while companies with a calendar fiscal year, beginning 1st January, 2006, received a six-month reprieve.

\section{Additional complicating factors}

The American Jobs Creation Act (AJCA) 2004 further complicates issues for companies by dramatically changing the tax rules applicable to nonqualified deferred compensation. Such compensation is now subject to tax when vested unless a company meets specific requirements relating to timing of deferral elections, distribution and funding. What is more, companies must have plans in compliance with the new AJCA rules by 31st December, 2005. Most stock options will meet an exemption to the rules if granted at fair value, but other equity-based deferred compensation may be subject to the AJCA requirements.

Adding urgency to the compliance deadline is the special audit initiative launched by the Internal Revenue Service (IRS) in 2004. During the past two years, the IRS has stepped up its review of employer nonqualified deferred compensation arrangements, specifically focusing on deduction timing and application of employment taxes on deferred amounts and withholding and reporting on stock option exercises.

Further, FAS 123R and the AJCA deferred compensation tax rules can potentially have a considerable impact on compliance with the Sarbanes-Oxley Act's requirements. Because of the possible material effects on financial reporting under Sarbanes-Oxley Section 302, companies 
must carefully consider how they characterise and document the impact of the standard on earnings. Ongoing internal controls must be put in place under Sarbanes-Oxley Section 404 to address the use of valuation methodologies, expense recognition of share-based pay, determination of deferred tax assets and tax provisions and the processes for assuring data quality and rewards programme administration, including outsourcing.

\section{An encompassing view of the landscape}

The distinct and overlapping requirements of FAS 123R, the AJCA and Sarbanes-Oxley have implications throughout the enterprise (see Figure 1).

Companies face the challenge of formulating an approach that addresses all these implications in a way that makes most sense for the business.

Such an approach should incorporate specific steps or phases, beginning with assessment and education and ending with design and implementation (see Figure 2).

\section{Assessment and education}

First, companies must take stock of where they are in the process of addressing the impact of
FAS 123R, the AJCA and Sarbanes-Oxley. They need to educate their executive team on compliance requirements in accounting, tax, valuation and equity-based compensation plan design, among many other areas.

Armed with this understanding, and taking the company's immediate needs and strategic goals into account, executives can then choose one of the two available options for adopting the revised standard. One choice, the 'modified prospective' method, requires companies to incorporate the appropriate expense in their income statements on a go-forward basis, and to expense all previously granted options that are nonvested and outstanding as of the adoption date. The other choice is the "modified retrospective' method, under which companies may elect to adopt FAS $123 \mathrm{R}$ by restating prior period amounts based on the expense calculated and reported in their pro forma footnote disclosures as previously required by FAS 123 .

Companies that are seeking to provide comparable financial statements from year to year would choose the modified retrospective method. This approach, however, requires additional efforts up-front in restating the balance sheet and income statements of prior years, which are

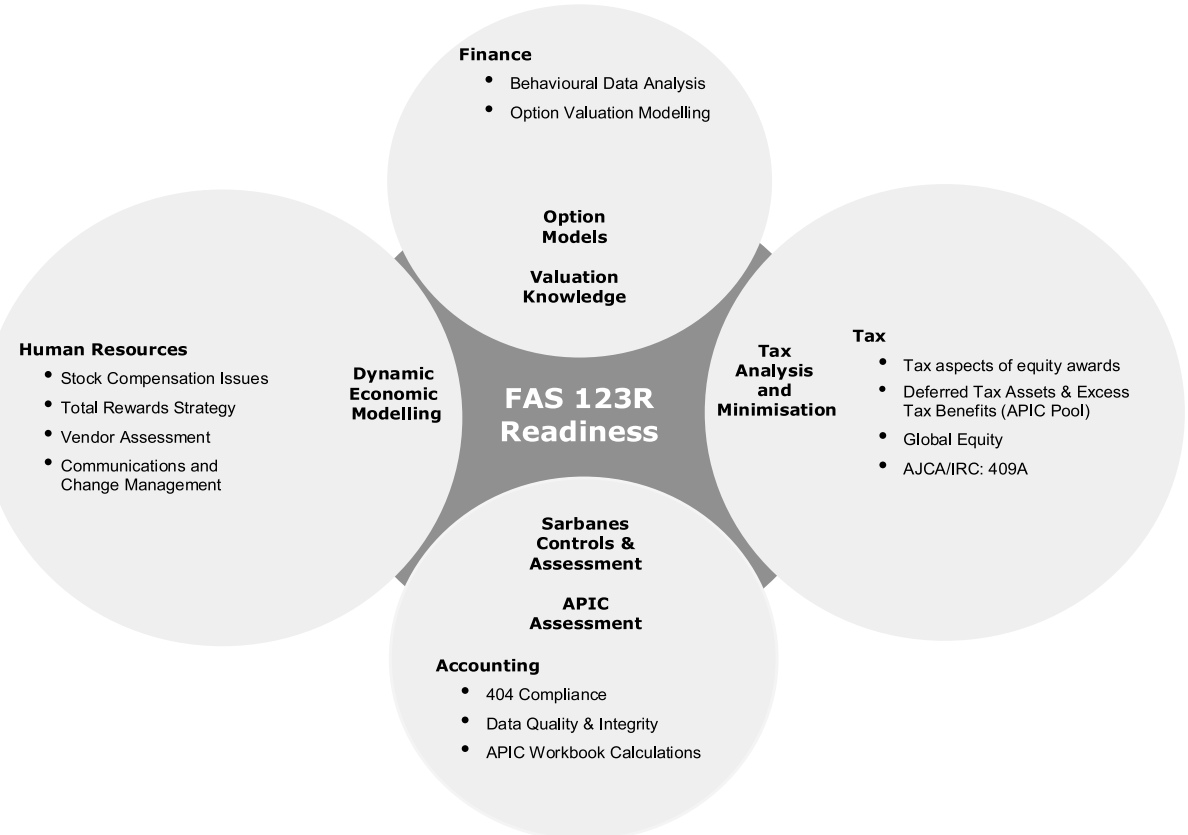

Figure 1: A comprehensive compliance view 


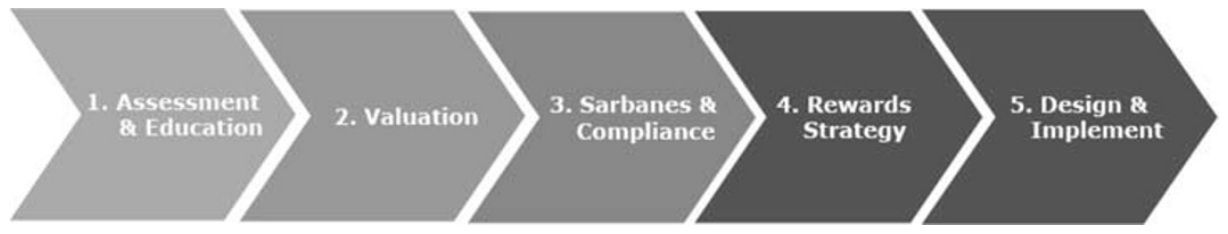

Figure 2: A multi-functional approach

required by the standard to match the pro forma amounts previously disclosed. Alternatively, companies that are not concerned with comparable financial statements and want to commit the least amount of up-front resources to comply with FAS $123 \mathrm{R}$ would choose the modified prospective approach.

\section{Valuation alternatives}

FAS 123R does not state a preference for a specific option valuation approach, but most companies will choose either the lattice-based model or the Black-Scholes-Merton formula to determine fair value of the options. It is, however, imperative to develop an appropriate valuation methodology and process controls for ongoing annual reviews, as the results of this calculation will flow through the income statement and impact the bottom line. Moving forward, companies will need to conduct the analysis in a consistent manner every time they grant options, especially when dealing with more complex considerations relating to forward volatility curves and statistical analyses of underlying data used to model employee exercise behaviour.

\section{Tax implications and the APIC pool}

In addition to choosing a valuation methodology and adoption method, companies will also need to determine their APIC pool. This calculation is based on the net cumulative effect, measured period-by-period, of all excess tax benefits and deficiencies related to stock awards granted since 1995 that would have been recognised had the company been accounting for stock awards under FAS 123R all along.

The importance of establishing and maintaining the pool is to avoid an income statement expense and hit to earnings for future option exercises or cancellations. For example, if a company's book expense on an option exercise is greater than the resulting tax deduction after adoption of FAS $123 \mathrm{R}$, the difference, adjusted for taxes, is applied against the existing APIC pool and does not affect the current financials. If there is no APIC pool, then the tax-adjusted difference must go directly to the income statement as an expense. If the deduction is greater than the book expense, then the tax-adjusted difference may be added to the APIC pool for future use.

This means that companies must analyse their option activity — specifically, stock-option exercises and cancellation - on a grant-by-grant basis. Most of this data is housed in stock-plan administrator software or other databases, but capturing it properly will likely be a challenge for many companies.

\section{Internal controls and compliance}

All new processes that are implemented will need to be disclosed. Thus, companies may want to consider having an outside adviser assist in the transition, as their independent auditors will review all the internal controls under SarbanesOxley Section 404, new tax rules applicable under the AJCA, employment tax compliance, global tax deductions and FAS 123R readiness. These reviews will include:

- option valuation and assumptions;

- evaluating the adoption methods (retrospective versus prospective);

- determining and tracking the FAS $123 \mathrm{R}$ APIC pool;

- establishing deferred tax assets and the tax provision;

- assessing stock-plan software capabilities and determining data quality. 


\section{Rewards strategy}

The new accounting, tax and internal control environment, simply put, is forcing a major rethinking of rewards programmes and their effect on shareholder value. Now that accounting for share-based pay is being tied to the bottom line, companies need to maximise employee productivity, commitment and the value of their rewards programmes. Companies need to get the most out of their rewards 'business'. It is time for companies to start running their total rewards activities like any other business with an equivalent impact on the enterprise.

Applying this approach to equity compensation means evaluating various stock plan designs, including domestic and global plans, to understand the potential costs and risks to the company - and balancing those factors against the benefits in terms of attracting, retaining and motivating employees to support the company's strategic objectives.

In turn, companies must deliver these new rewards programmes to executives and employees as efficiently and effectively as possible, clearly communicating both the advantages the programmes offer and the compliance requirements surrounding them. This means looking at rewards administration and operations anew to make sure that the company complies with all relevant laws and regulations, effectively oversees relationships with rewards service providers and manages costs and risks within clear parameters. By instilling a high level of discipline around day-to-day rewards administration, companies will be better able to take a proactive, well-informed approach to their talent management and rewards programmes.

\section{Performance-based compensation}

When it comes to performance-based compensation plans, most US companies are behind the rest of the world. This may be largely due to the traditional US accounting treatment that made plans that employ performance metrics subject to variable rather than fixed accounting. This meant that performance-based pay plans would generate an accounting charge where one would not otherwise have existed, making them unattractive for widespread use in the USA. Where US companies have used performance measures, they have been very piecemeal, either to avoid the limitations of Section 162(m) of the tax code, which limits the corporate tax deduction for the top five executives, or to enable acceleration of vesting for what are essentially still time-vested awards.

European countries, on the other hand, have been using performance linking for many years. In the UK, for example, performance metrics are almost universal for quoted companies. This has been the case since 1987, because institutional shareholders have voted down any new plan that does not involve relevant performance targets. In Germany, performance hurdles are actually required by law. These are just two examples but they illustrate that European countries have a wealth of experience with performance plans.

Now, though, the FAS $123 \mathrm{R}$ and AJCA changes have put US companies on a level playing field with their European counterparts with regard to accounting for performance-driven compensation. With equity compensation now hitting the books anyway, US companies now have nothing to lose - and potentially a great deal to gain - by using incentive plans that drive strategic and financial gains, just as non-US companies have been doing for years. It is hard to think of any reason why the kinds of programmes seen outside the USA will not work just as well in the USA.

\section{It is time...}

FAS $123 \mathrm{R}$ and the AJCA have rattled many companies in the months since they were issued, but now that companies have had time to review the new regulations, it is time to get to work on determining the best route for implementation. A comprehensive approach to FAS 123R - while considering the implications of AJCA and Sarbanes-Oxley - can generate programme and process improvements that lead to competitive advantage.

All of this adds up to an opportunity for companies to reconsider their equity compensation plans and the prospect to design new employee rewards programmes that can 
minimise financial expense, tax cost and compliance risk while meeting their overall business objectives.

Not only can well-prepared companies reduce the financial, operational and reputational risks associated with noncompliance, but they can also leverage new opportunities for creating an environment that attracts high-quality executives and employees. It can be done; now is the time to make it happen.

(C) 2006 Deloitte Development LLC 